\title{
As organizações sociais de saúde como forma de gestão público- privada em Goiás - o caso Huana ${ }^{1}$
}

\author{
Nelson Bezerra Barbosa \\ Centro Universitário de Anápolis (UniEvangélica) \\ Helen de Lima \\ Centro Universitário de Anápolis (UniEvangélica)
}

Andrei Machado Viegas da Trindade

Centro Universitário de Anápolis (UniEvangélica)

Natália Vieira Dias

Centro Universitário de Anápolis (UniEvangélica)

Mariana Vilela de Castro

Centro Universitário de Anápolis (UniEvangélica)

Caroline Kwiatkoski dos Santos

Centro Universitário de Anápolis (UniEvangélica)

O presente trabalho teve como objetivo descrever o processo de implantação da figura jurídica organização social (OS) na gestão de unidades hospitalares em Goiás. Tratase de estudo exploratório-descritivo, do tipo estudo de caso, do processo de implantação desse modelo gerencial. As categorias de análise englobam: caracterização da unidade, arcabouço jurídico-normativo do processo de implantação da unidade, acompanhamento e avaliação do desempenho da unidade, e gestão de recursos humanos e materiais. Os dados e informações levantados no presente trabalho assinalam algumas vantagens competitivas desse modelo, ao mesmo tempo em que apontam para algumas dificuldades internas ao setor público em acompanhar e avaliar os objetivos e metas acordados nos contratos de gestão. Sugere-se a continuidade de trabalhos como o que foi aqui desenvolvido junto a outras unidades que incorporaram o modelo OS.

Palavras-chave: modelo de gestão, administração hospitalar, parceria público privada, administração estadual

\footnotetext{
${ }^{1}$ Artigo baseado em relatório final de Projeto de Pesquisa (Pibic).
}

Artigo recebido em novembro de 2013. Versão final em agosto de 2014. 
Las Organizaciones Sociales de Salud como Forma de Gestión Público / Privado en Goiás el caso HUANA

Este trabajo tuvo como objetivo describir el proceso de aplicación de la figura legal Organización Social en la gestión de las unidades hospitalarias en Goiás. Es un estudio exploratorio-descriptivo, del tipo Estudio de Caso, del proceso de implementación de este modelo de gestión. Las categorías de análisis son: la caracterización de la unidad; el diseño legal-normativo del proceso de implementación de la unidad; el seguimiento y la evaluación del rendimiento de la unidad; la gestión de los recursos humanos y materiales. Los datos y la información recogidos en este estudio indican algunas de las ventajas competitivas de este modelo, mientras apuntan para algunas dificultades internas al sector público para monitorear y evaluar los objetivos y las metas establecidos en los contratos de gestión. Se sugiere la continuidad de los trabajos como el desarrollado aquí junto a otras unidades que incorporan el modelo OS .

Palabras clave: modelo de gestión, administración de hospitales, asociación públicoprivada, comunidades autónomas

\section{Health Social Organizations as a way of public-private management in the state of Goiás (Brazil): HUANA case}

This study aimed to describe the process of implementation of the legal concept Social Organization in the management of hospitals in the state of Goiás. It is an exploratorydescriptive case study of the process of implementing this management model. The categories of analysis comprise: characterization of the unity; legal-normative outline of the process of the unit deployment; monitoring and evaluation of the performance of the unit; management of human and material resources. The data and information collected in this study indicate some competitive advantages of this model, while pointing to internal difficulties in the public sector to monitor and evaluate the goals and targets agreed in the management contracts. Future studies are suggested, such as the one developed here, with other units that have joined the Social Organization model.

Keywords: management model, hospital administration, public-private partnership, state government 


\section{Introdução}

O Sistema Único de Saúde (SUS) tem enfrentado, como principal desafio ao seu processo de consolidação, a melhoria da sua capacidade de gestão. Esse desafio implica eficiência no uso dos recursos, considerados escassos quando comparados ao volume de pessoas que dependem exclusivamente dos serviços ofertados pelo SUS (70\% da população é usuária exclusiva do sistema). O desafio também se mede pela magnitude dos problemas, que combina um perfil demográfico e epidemiológico em transição - envelhecimento populacional e prevalência cada vez maior de doenças crônico-degenerativas.

As respostas que têm sido buscadas estão orientadas por um esforço dirigido à descentralização, com importante e significativo papel dos municípios na prestação de serviços e ações, com aumento do volume de recursos destinados ao setor, com investimento em formação e capacitação dos trabalhadores e busca de novos modelos de gestão, sobretudo para as unidades hospitalares, considerando a complexidade do processo de gerenciamento dessas. As experiências de implementação de novos modelos de gestão têm como matriz a crise do Estado e as propostas decorrentes ao seu enfrentamento.

As reformas do Estado referidas alcançam o Brasil nos anos de 1990 e têm como discurso a crítica à rigidez burocrática e a necessidade de mudanças, com a incorporação dos princípios da nova gestão pública. Os princípios que nortearam a reforma do Estado têm influenciado e incentivado o desenvolvimento da inovação no setor público, com desdobramentos para o setor da saúde (BARBOSA; ELIAS, 2010).

A escolha por um modelo público e universal sinaliza para a primeira grande inovação no setor, considerando que até então o que existia era um sistema previdenciário, em que o acesso a serviços de saúde oferecidos pela rede pública estava condicionado ao pagamento de contribuição para o sistema. Os serviços de saúde, portanto, estavam organizados na base de um mix de sistema meritocrático e residual, ou seja, os que estavam formalmente inseridos no mercado de trabalho tinham direito a consumir ações e serviços médicos hospitalares, na rede do antigo Instituto Nacional de Assistência Médica e Promoção Social (Inamps) ou na rede conveniada ao Instituto Nacional de Previdência Social (INPS). Aos excluídos do mercado, restava recorrer aos poucos serviços oferecidos por secretarias estaduais ou municipais, ou ainda à filantropia. Dessa forma, incorporar o conjunto da população brasileira ao SUS foi a grande inovação em termos de política pública de saúde no Brasil (COHN; ELIAS, 2003).

Desenhar e implementar a arquitetura desse sistema, dentro de um processo de gestão compartilhada entre os três entes federados - União, Estados e Municípios -, demandou, e continua demandando, um esforço criativo. O pacto federativo que vem 
sendo desenvolvido em torno do setor implicou concertação das responsabilidades sanitárias, de gestão e de financiamento do sistema, além da organização de processos decisórios internos ao setor que não podem ser realizados sem a participação das três esferas de governo e sem a efetiva participação da sociedade, representada nos conselhos e na conferência de saúde, por usuários, trabalhadores e prestadores de serviços (CAMPOs et al., 2007).

O esforço para aprimorar esse arranjo organizacional passou por diversas etapas e momentos, dos quais o mais recente foi o Pacto pela Saúde. Esse instrumento de gestão abrange três dimensões: o Pacto pela Vida, o Pacto de Gestão e o Pacto em Defesa do SUS. O primeiro está focado na gestão por resultados, com definição de objetivos e metas a serem cumpridos pelos gestores em cada nível de governo; o segundo está voltado para a permanente discussão sobre a distribuição de responsabilidades entre os entes federados; e o último representa um compromisso político em defesa do sistema, com vistas à sua institucionalização como política de Estado e não de governos (BRASIL, 2006).

O Decreto no 7.508/2011 introduz novos desafios ao processo de organização do SUS com a reintrodução do tema da regionalização, ou seja, da necessidade de adoção de um modelo de organização dos serviços em bases regionais. A tomada de decisões no âmbito do sistema impõe a estruturação de um novo espaço de gestão (os colegiados intergestores regionais) e a introdução de um novo instrumento resultante da concertação feita nesse nível do sistema - o Contrato de Organização da Ação Pública (Coap). A imagem-objetivo a ser perseguida é a da gestão e financiamento por resultados e a definição de responsabilidade entre os gestores quanto ao alcance destes resultados, com a possibilidade de adoção de medidas legais sobre gestores que não cumprirem metas estabelecidas (BRASIL, 2011).

Nesse contexto, a gestão de unidades hospitalares, pela sua enorme complexidade, custo e importância na rede de atenção à saúde, tem merecido um olhar especial e se tornado objeto de proposições. Entre as propostas, a que ganhou maior destaque foi a da criação de organizações sociais de saúde (OSS), que teve seu início por decisão do Governo do Estado de São Paulo. Essas novas figuras jurídicas, derivadas da reforma administrativa de 1995, delegam a organizações públicas não estatais a tarefa de gerenciar, em nome do poder público, unidades hospitalares de propriedade pública estatal. A relação dessas organizações públicas com o Estado é mediada por um contrato de gestão que estabelece objetivos, metas e compromissos entre as partes (BARBOSA; Elias, 2010).

Atualmente, essa experiência é a que se encontra disseminada em maior grau no País, com o Estado de São Paulo sediando o maior número de unidades gerenciadas 
por esse modelo. Em Goiás, todas as unidades hospitalares de propriedade da Secretaria de Estado da Saúde de Goiás (SES-GO) funcionam dentro da modalidade OS, entre elas o Hospital de Urgências de Anápolis (Huana).

A experiência investigada demonstra vantagens em relação ao sistema de aquisição de bens e serviços, por sua flexibilidade e agilidade; adoção de metas de referência quanto ao uso dos recursos existentes (capacidade instalada); implantação de uma cultura de monitoramento e avaliação de resultados, comparativamente aos procedimentos adotados na administração pública. Essas vantagens, entretanto, para serem potencializadas, demandam a melhoria nos mecanismos de controle por parte do setor público. Esse aparente paradoxo se observa nas constantes revisões das metas adotadas no contrato de gestão da unidade investigada.

Trabalhos como o relatório do Tribunal de Contas do Estado (TCE, 2010), Ibañez (2001), Barbosa e Elias (2010) indicam possibilidades e limites do modelo. Destacamse, por exemplo, ganhos de produtividade e nos processos de aquisição de bens e serviços, bem como as dificuldades quanto à integração dessas unidades na rede, aos riscos da seleção de clientela e as dificuldades para operar controle sobre uma lógica que não se incorporou na cultura de funcionamento da administração pública - a gestão por resultados.

O trabalho aqui apresentado buscou desenvolver um estudo exploratóriodescritivo sobre o modelo OS em Goiás, usando o Huana como caso. A instituição habilitada como organização social para gerir essa unidade foi a Fundação de Assistencia Social de Anápolis (Fasa), coordenada pela Santa Casa de Misericórdia de Anápolis. As categorias de análise estão referidas às dimensões propostas para estruturação dos dados, englobando: caracterização da unidade, arcabouço jurídiconormativo do processo de implantação da OS, acompanhamento e avaliação do desempenho da unidade, gestão de recursos humanos e materiais. O marco teórico que embasa o processo de implantação dessa modalidade de gestão está referido à crítica do modelo burocrático de gestão e à emergência da perspectiva gerencial aplicada à administração pública, na perspectiva do aumento da eficiência.

Foram utilizados como fontes secundárias documentos relativos ao processo de implantação e desenvolvimento do modelo gerencial proposto (OS), tais como: legislação que normatiza o processo de habilitação de entidades como organizações sociais; contratos de gestão firmados entre a SES-GO e Fasa; relatórios de acompanhamento da execução do contrato, elaborados pela Controladoria Interna do Estado. As fontes primárias foram constituídas por técnicos da Controladoria Interna (dois), gestores da Superintendência de Controle e Avaliação Técnica em Saúde (SCATS/SES-GO) (dois), gerentes e técnicos do Huana (quatro). 


\section{Transição demográfica e epidemiológica: repercussões sobre as políticas de saúde}

O Brasil enfrenta um processo de transição demográfica e epidemiológica com impactos importantes sobre o processo de formulação e implementação de políticas públicas em saúde. O envelhecimento populacional tem alterado a pirâmide etária, caracterizada pela compressão em sua base e expansão do topo. A expectativa de vida, que era de 60 anos na década de 1980, saltou para 73,4 anos no ano de 2010. Por outro lado, a taxa de fecundidade, que, em 1970, era de 5,8 filhos nascidos de uma mulher brasileira, em 2010, foi de 2,4 filhos (IBGE, 2010).

Outro fenômeno demográfico importante diz respeito ao processo de urbanização. Em 1970, o percentual de residentes em áreas urbanas era de 55,9\%; em 2007, esse número se elevou para 83,5\%. A concentração populacional em regiões metropolitanas provoca demanda intensa por serviços públicos, promove degradação ambiental por meio de ocupação desordenada e impacta negativamente na qualidade de vida e saúde das populações (IBGE, 2010).

Essas transformações demográficas repercutem sobre o perfil de morbidade, caracterizado por uma associação entre doenças infecto-contagiosas e crônicodegenerativas. Por sua vez, o padrão de mortalidade apresenta forte concentração de três principais causas: doenças do aparelho circulatório (infartos e acidentes vasculares), neoplasias e causas externas (violência intencional e não intencional). O aumento da população idosa e os riscos inerentes a esse processo, associados a mudanças de hábitos e padrão de consumo, baixa qualidade de vida e fatores estressantes provocados por problemas socioambientais, são determinantes para essa situação de saúde prevalente hoje no País, sobretudo nos grandes centros (RIBEIRO, 2014).

Esse quadro tem contribuído para uma demanda crescente por serviços de urgência, que faz com que esse setor venha se constituindo em principal porta de entrada do sistema. O volume dos casos de acidentes e violências se expressa no registro de 700 mil internações por ano no Sistema de Informações Hospitalares (SIH) e R\$ 661 milhões de gastos hospitalares no ano de 2007 decorrentes do aumento dos níveis de violência (BRASIL, 2008).

O desafio de prestar assistência para a população, sobretudo para aquela que é usuária exclusiva do sistema, tem levado os gestores a buscar modelos alternativos para um gerenciamento mais eficiente dos recursos. $O$ fato de lidar com o risco de morte ou de comprometimento de funções importantes para autonomia e independência dos sujeitos implica capacidade de decidir e agir rápido. Nesse contexto, o modelo burocrático tem se mostrado inadequado ao bom funcionamento 
do sistema, demandando a emergência de novos paradigmas e formatos para a administração pública em geral, e para o setor da saúde em particular.

Ganha força, nesse cenário, uma perspectiva de administração gerencial como enfoque a ser adotado para o setor público. O modelo gerencial, a despeito de sua matização, guarda alguns princípios comuns, como reação ao desperdício, incentivos ao desempenho (com separação entre financiamento e provisão) e foco na eficiência. A mudança mais substancial patrocinada pelo surgimento desse novo paradigma está relacionada à formação de paramercados (quase mercados), com a introdução da contratação e seus desdobramentos sobre o comportamento organizacional.

A ideia central contida na noção de paramercados é a de estimular a introdução de mecanismos de mercado dentro do serviço público, estimulando a competição no seu interior. Os contratos firmados entre compradores e executores (contratos de gestão) se propõem a estimular e premiar a eficiência da organização de serviços prestados, dentro da lógica de que o recurso deve seguir o usuário (BRESSER PEREIRA, 2010).

A implementação de reformas foi orientada por alguns princípios e diretrizes que convergem em direção à descentralização e busca de eficiência. No caso do Brasil, a descentralização consistiu na privatização de uma série de atividades econômicas desenvolvidas pelo Estado, na transferência da execução das políticas públicas a instâncias sub-nacionais e na incorporação de entes públicos não estatais às tarefas de gerenciamento e execução de ações (no que ficou conhecido como processo de publicização). Esse último aspecto ensejou o surgimento das organizações sociais (OS), objeto de discussão deste trabalho.

O Plano Diretor da Reforma do Aparelho de Estado (PDRAE), documento que orienta a reforma gerencial brasileira, estabelece como diretrizes: a descentralização e a desconcentração, a introdução do conceito de setor público não estatal, o controle sobre resultados, a desregulamentação do trabalho e a nova política de recursos humanos (CARNEIRO JúNIOR; ELIAS, 2006).

A inauguração desse novo modelo de interação entre Estado e sociedade, informada pela obtenção de resultados, articula características como autonomia, flexibilidade e responsabilidade na gestão. Cabe ao Estado, nessa parceria, o financiamento total ou parcial, e às organizações selecionadas, a prestação dos serviços indicados, responsabilizando-se por resultados acordados em contratos de gestão. Esse instrumento de gestão tem sido adotado para ordenar a relação entre entes da administração direta e indireta (ministérios e agências, por exemplo), mas também entre entes públicos e organizações da sociedade civil para fins do exercício do princípio da publicização adotado na reforma administrativa de 1995 (BRESSER PEREIRA, 2010).

O desempenho esperado pelas OS, firmado nesse contrato, é objeto de monitoramento e avaliação permanentes, definindo perspectivas de continuidade 
ou não desse contrato. Essa avaliação deve considerar não apenas critérios de eficiência, eficácia e efetividade, como também valores públicos (CorRÊA, 2007; CARNeIRo Júnior; Elias, 2006; BARBosa; Elias, 2010).

O Governo do Estado de Goiás adotou, em 2002, o modelo de gestão OS para o setor da saúde, com a implantação do Centro de Reabilitação e Readaptação Dr. Henrique Santillo (Crer), sob gestão da Associação Goiana de Integralização e Reabilitação (Agir). Esse modelo hoje abrange a totalidade das unidades hospitalares de propriedade da Secretaria de Estado da Saúde. Entretanto, a expansão desse modelo tem sido feita sem a realização de trabalhos voltados para a apreensão do modelo, quanto aos seus limites e possibilidades. O presente trabalho objetiva descrever essa experiência em uma unidade hospitalar (Hospital de Urgências de Anápolis - Huana), sem a pretensão de extrapolar suas conclusões ao conjunto das demais unidades identificando características gerais do processo de implementação dessa experiência gerencial.

\section{Resultados e discussão}

\section{Caracterização da unidade}

O Hospital de Urgências de Anápolis Dr. Henrique Santillo (Huana) insere-se no esforço institucional de criar uma rede de serviços de urgências, capaz de atender a uma demanda crescente nessa área. A mortalidade por causas externas é a terceira causa de mortalidade no estado, sendo que, em alguns municípios, ela já se coloca como a segunda (DATASUS, 2010). Essa situação faz com que as unidades de urgência dividam com as unidades de atenção primária a função de porta de entrada de usuários no sistema.

Esse quadro de demanda crescente por serviços dessa natureza, ocasionado por uma série de causas traduzidas pelo caótico processo de urbanização, baixa resolubilidade na atenção primária e processos de trabalho na assistência mal desenhados, resultava em volume de procura que sobrecarregava a principal unidade do estado - o Hospital de Urgências de Goiânia (Hugo). Entre as medidas para controlar esse fluxo em direção ao Hugo, ampliando a oferta de pontos de acesso à emergência, está a da criação de unidades em regiões estratégicas para contenção dessa demanda, entre elas o Hospital de Urgência de Anápolis.

Essa unidade possui uma área física total de $10.000 \mathrm{~m}^{2}$, com uma área construída de $8.000 \mathrm{~m}^{2}$. Possui a seguinte distribuição de leitos: 39 leitos de internação, 24 de observação, 11 para UTI adulto e 07 para UTI infantil e neonatal, com um total, portanto, de 81 leitos.

Os serviços prestados por essa unidade envolvem cirurgia geral, ortopédica, neurológica, vascular, bucomaxilofacial e pediátrica. A área de Apoio Diagnóstico 
e Terapêutico (SADT) oferta serviços de eletrocardiograma, análises clínicas, tomografia, radiologia, ultrassonografia e de transfusão. A área de apoio conta com serviços de nutrição, psicologia, farmácia, fisioterapia, entre outros.

O quantitativo de recursos humanos do Huana é de 452 trabalhadores, distribuídos entre as seguintes categorias:

- enfermagem (nível médio e superior) - 209;

- apoio (nutrição, psicologia, serviço social, segurança, limpeza, telefonia, motorista, serviços técnicos) - 79;

- administrativos - 60;

- médicos - 96;

- cirurgião bucomaxilofacial - 08 (FASA, 2010).

A implantação de unidades desse tipo tem como objetivo a organização e fortalecimento de redes regionais de saúde com suficiência para atender a maioria das demandas de sua população. A estratégia de descentralização da oferta desses serviços implicou a criação desses hospitais, que devem estar integrados ao conjunto de serviços da região. Nesse caso, a expectativa é que o Huana se constitua na referência para a área de urgência no âmbito da Região Pireneus. Essa região engloba os Municípios de Alexânia, Abadiânia, Anápolis, Campo Limpo de Goiás, Gameleira de Goiás, Goianápolis, Teresópolis de Goiás, Cocalzinho de Goiás, Pirenópolis e Corumbá de Goiás. A população dessa região é de aproximadamente 400 mil habitantes (DATASUs, 2010).

\section{Arcabouço normativo do processo de implantação da OS}

A figura jurídica denominada organização social emerge com a proposta de reforma administrativa de 1995, no Governo FHC, articulada e implementada pelo Ministério da Administração e Reforma do Estado (Mare), sob a coordenação do Ministro Bresser Pereira. A motivação desse projeto de reforma é o propósito de inserir o País, no âmbito da administração pública, na segunda grande onda de reformas orientadas pelo princípio da eficiência e da efetividade das organizações do setor público. A estratégia aponta para o desenvolvimento de novas relações público-privadas. No contexto do setor da saúde, a interação entre esses segmentos, que até então se dava no campo da compra e venda de serviços, foi ampliada para a inserção do setor público não estatal na função gerencial de ações e serviços.

Fundamentalmente, o processo de implementação do Programa Nacional de Publicização propõe que as instituições privadas que atuam em áreas de interesse público possam ser habilitadas como gerenciadores de instituições prestadoras de serviços nas áreas de educação, saúde, cultura, esporte e lazer. O primeiro passo, 
portanto, foi a aprovação de legislação criando essa nova figura jurídica (OS), definindo que organizações da sociedade civil poderiam ser habilitadas como tal e as regras para sua habilitação.

A lei no 9.637, de maio de 1998, instrumento jurídico que serve de base para criação de entidades, em relação à qualificação de entidades como OS, define que:

O Poder Executivo poderá qualificar como organizações sociais pessoas jurídicas de direito privado, sem fins lucrativos, cujas atividades sejam dirigidas ao ensino, à pesquisa científica, ao desenvolvimento tecnológico, à proteção e preservação do meio ambiente, à cultura e à saúde, atendidos aos requisitos previstos nesta lei (BRASIL, 1998).

Essa norma geral orienta o processo de criação e habilitação das organizações sociais nas três esferas de governo. O primeiro estado brasileiro a admitir essa modalidade de gestão foi São Paulo, por meio da Lei Complementar no 846, de 4 de junho de 1998 (SÃo PAULO, 1998). Em Goiás, a norma sobre essa nova forma de gestão está descrita na lei no 15.503, de 28 de dezembro de 2005. Com base nessa lei, o Executivo estadual habilitou a Fundação de Assistência Social de Anápolis como organização social, entregando a ela a gerência do Huana (GoIÁs, 2005).

De maneira geral, as legislações são bastante convergentes, sobretudo quanto ao poder discriminatório do chefe do Executivo para indicação de OS habilitadas a gerir instituições enquadradas no rol de atividades descritas na lei no 9.637/98 (BRASIL, 1998). Entretanto, é possível observar algumas diferenças em relação a aspectos fundamentais para a administração pública em geral, como para o SUS em particular.

O processo de habilitação de entidades da sociedade civil como organizações sociais fixa um conjunto de condições de ordem jurídico-administrativa que informa as atividades que podem ser cobertas por essa modalidade de gestão, as condições do ponto de vista de seus estatutos (que indicam a natureza não lucrativa dessas), a composição da estrutura administrativa, bem como a observância à prestação de contas em relação às metas fixadas. Como a habilitação depende do poder discriminatório do chefe do Executivo, a norma em Goiás é omissa quanto à exigência de experiência prévia na gestão de serviços por parte da OS (GoIÁs, 2005). Em São Paulo, os legisladores optaram pela exigência de experiência de no mínimo cinco anos como critério para qualificação das OS (SÃo PAULO, 1998). Esse item pode ter repercussão direta sobre a capacidade de realizar uma administração eficiente dos recursos disponíveis e, consequentemente, sobre o alcance das metas.

Entre esses aspectos diferenciadores, vale a pena destacar a preocupação dos legisladores do Estado de São Paulo em afirmar o uso dos serviços de saúde gerenciados por OS para usuários exclusivamente do SUS, ou seja, a experiência 
de São Paulo vedava a utilização da capacidade instalada desses serviços para portadores de planos e seguros de saúde, impedindo a formação da chamada dupla porta de entrada. A legislação de Goiás é omissa nesse aspecto, o que permitiu ao Centro de Reabilitação e Readaptação Dr. Henrique Santillo (Crer) reservar 30\% de sua produção para atendimento de clientela do setor privado. Essa permissão foi recentemente revogada, por meio de cláusula ao termo aditivo do contrato de gestão celebrado entre a Secretaria de Estado da Saúde e a OS que administra essa unidade (GoIÁs, 2012).

O Quadro 1 apresenta a síntese dessas convergências e dessemelhanças entre as legislações federal, de São Paulo e Goiás, relativas ao processo de habilitação de entidades da sociedade como organizações sociais.

A decisão quanto à possibilidade de uso de recursos de unidades públicas de saúde para atendimento de portadores de planos e seguros de saúde é tema bastante controverso, que ensejou pedido de Ação Direta de Inconstitucionalidade (Adin) contra as organizações sociais, que até o presente momento aguarda julgamento por parte do Supremo Tribunal Federal (STF). Para além de questões de ordem legal ou político-ideológica, há o questionamento quanto à capacidade de o poder público controlar esse tipo de acesso, que pode ser fonte de iniquidade no sistema. No presente momento, esse procedimento não se aplica no Huana, mas a legislação não impede que os gestores do setor venham a fazê-lo.

Vale a pena destacar que a nova legislação vigente no Estado de Goiás quanto à qualificação de entidades da sociedade civil como organizações sociais pouco acrescenta em relação às regras anteriores, mantendo posição omissa quanto à venda de serviços a planos e seguros de saúde, ou seja, não veda a possibilidade de constituição de dupla porta de entrada a unidades gerenciadas por OS (GoIÁs, 2013).

O debate jurídico, a despeito dos dois votos até aqui pronunciados e que se inclinam a favor da legalidade do modelo OS, não está encerrado. Entretanto, a perspectiva é de que a realidade se imponha como fato e defina ao final a posição da suprema corte a favor dessa experiência. Nesse momento, 100\% das unidades hospitalares geridas pela SES-GO estão incorporadas a esse modelo (GoIÁs, 2014). São Paulo tem uma longa experiência de implantação do modelo, com quase 4000 leitos administrados sob essa modalidade (ELIAS; BARBOSA, 2010). O Governo da Bahia construiu a primeira unidade hospitalar no formato parceria público-privada (PPP), com gestão OS (COTTA, 2012). A busca de alternativas ao processo de gestão de recursos públicos, respaldada em legislação derivada da reforma administrativa de 1995, tem caminhado no sentido da consolidação desses novos formatos administrativos. 
Quadro 1: Comparativo da legislação referente à criação de organizações sociais Brasil, São Paulo e Goiás - 2010

\begin{tabular}{|c|c|c|c|}
\hline Itens da legislação & Brasil (1998) & Goiás (2005) & São Paulo (1998) \\
\hline $\begin{array}{l}\text { Composição do } \\
\text { Conselho de Adminis- } \\
\text { tração (CA) }\end{array}$ & $\begin{array}{l}\text { Membros Natos ( }>50 \% \\
\text { e indicados na forma do } \\
\text { estatuto). } \\
\text { Eleitos (<50\%) - indicado } \\
\text { entre os membros do CA } \\
\text { ou por esses. } \\
\text { Não prevê participação do } \\
\text { controle social. } \\
\text { O 1o mandato de metade } \\
\text { dos membros eleitos ou } \\
\text { indicados deve ser de dois } \\
\text { anos, segundo critérios } \\
\text { estabelecidos no estatuto. } \\
\text { O dirigente máximo da } \\
\text { entidade deve participar } \\
\text { das reuniões do conselho, } \\
\text { sem direito a voto. } \\
\text { O conselho deve se reunir } \\
3 \text { vezes ao ano. }\end{array}$ & $\begin{array}{l}\text { O mesmo se observa } \\
\text { neste item. }\end{array}$ & $\begin{array}{l}\text { Não incorpora } \\
\text { a figura do membro } \\
\text { nato. } \\
\text { Os membros eleitos } \\
\text { entre os associados } \\
\text { devem representar } \\
55 \% \text {. } \\
\text { Inclui a participação } \\
\text { de empregados da } \\
\text { entidade (10\%). } \\
\text { Veda a participação } \\
\text { de membros que te- } \\
\text { nham laços consan- } \\
\text { guíneos. }\end{array}$ \\
\hline $\begin{array}{l}\text { Atribuições do } \\
\text { Conselho de } \\
\text { Administração }\end{array}$ & $\begin{array}{l}\text { Fixar o âmbito de } \\
\text { atuação da entidade. } \\
\text { Aprovar contrato de } \\
\text { gestão. } \\
\text { Aprovar orçamento e pro- } \\
\text { grama de investimentos. } \\
\text { Aprovar regulamento de } \\
\text { contratação de bens e } \\
\text { serviços. } \\
\text { Aprovar e encaminhar } \\
\text { relatórios gerenciais das } \\
\text { atividades da entidade. } \\
\text { Fiscalizar cumprimento de } \\
\text { diretrizes e metas. } \\
\text { Aprovar demonstrativos } \\
\text { financeiros. }\end{array}$ & $\begin{array}{l}\text { Conteúdos } \\
\text { convergentes. }\end{array}$ & $\begin{array}{l}\text { Segue as } \\
\text { diretrizes da } \\
\text { norma nacional. } \\
\text { Veda a participação } \\
\text { de membros do CA } \\
\text { em cargos de } \\
\text { confiança no SUS. }\end{array}$ \\
\hline
\end{tabular}




\begin{tabular}{|c|c|c|c|}
\hline Itens da legislação & Brasil (1998) & Goiás (2005) & São Paulo (1998) \\
\hline $\begin{array}{l}\text { Contrato de gestão } \\
\text { (CG) }\end{array}$ & $\begin{array}{l}\text { Elaborado conjuntamente } \\
\text { entre OS e órgão ou enti- } \\
\text { dade supervisora. } \\
\text { Aprovação pelo CA e envio } \\
\text { ao Gov. do estado ou secre- } \\
\text { tário da pasta. } \\
\text { Especifica programa pro- } \\
\text { posto pela OS e metas a } \\
\text { serem alcançadas, prazos e } \\
\text { critérios de avaliação. } \\
\text { Estipula limites e critérios } \\
\text { para gasto com pessoal. } \\
\text { Estabelece que bens móveis } \\
\text { e imóveis devem ser gastos, } \\
\text { exclusivamente, com execu- } \\
\text { ção do CA. } \\
\text { OS deve entregar ao fim } \\
\text { de cada exercício relatório } \\
\text { referente à execução do CG. } \\
\text { Irregularidades detecta- } \\
\text { das na execução do CG } \\
\text { devem ser comunicadas } \\
\text { ao Tribunal de Contas do } \\
\text { Estado (TCE) e AL. }\end{array}$ & $\begin{array}{l}\text { Texto da lei de } \\
\text { Goiás tem a mesma } \\
\text { redação. } \\
\text { Detalha mais, } \\
\text { entretanto, sobre } \\
\text { possíveis sanções a } \\
\text { dirigentes das OS em } \\
\text { caso de irregulari- } \\
\text { dades administra- } \\
\text { tivas identificadas, } \\
\text { incluindo sequestro } \\
\text { dos bens dos admi- } \\
\text { nistradores da OS. } \\
\\
\text { Especifica que, } \\
\text { em caso de ação } \\
\text { judicial, o poder } \\
\text { público passa a ser } \\
\text { gestor dos bens e } \\
\text { responsável pela } \\
\text { manutenção das } \\
\text { atividades. } \\
\text { Omissa em } \\
\text { relação ao atendi- } \\
\text { mento exclusivo aos } \\
\text { usuários do SUS. }\end{array}$ & $\begin{array}{l}\text { Afirma necessidade } \\
\text { das OS habilitadas } \\
\text { seguirem os princí- } \\
\text { pios do SUS } \\
\text { (Art. } 198 \text { da CF e } \\
\text { Art. } 7 \text { da 8080). } \\
\text { Dispensa de licitação } \\
\text { para celebração } \\
\text { desses contratos. } \\
\text { Contrato de gestão, } \\
\text { após aprovado pelo } \\
\text { CA, deve ser subme- } \\
\text { tido ao Secretário de } \\
\text { Saúde. } \\
\text { Atendimento exclu- } \\
\text { sivo aos usuários do } \\
\text { SUS. } \\
\text { Comissão de } \\
\text { Avaliação dos } \\
\text { contratos de gestão } \\
\text { deverá ter entre } \\
\text { seus membros dois } \\
\text { representantes do } \\
\text { Conselho Estadual } \\
\text { de Saúde e dois da } \\
\text { Comissão de Saúde } \\
\text { da AL. } \\
\text { Afirma o direito de } \\
\text { qualquer cidadão, } \\
\text { partido político ou } \\
\text { entidade sindical de } \\
\text { apresentar denúncia } \\
\text { sobre irregularidades } \\
\text { percebidas. }\end{array}$ \\
\hline
\end{tabular}




\begin{tabular}{|l|l|l|l|}
\hline \multicolumn{1}{|c|}{ Itens da legislação } & \multicolumn{1}{|c|}{ Brasil (1998) } & \multicolumn{1}{c|}{ Goiás (2005) } & \multicolumn{1}{c|}{ São Paulo (1998) } \\
\hline $\begin{array}{l}\text { Fomento às } \\
\text { atividades sociais }\end{array}$ & $\begin{array}{l}\text { Detalhamento sobre } \\
\text { cessão de bens com base } \\
\text { na permissão de uso. } \\
\text { Sobre permuta de bens na } \\
\text { OS, condicionada a sua in- } \\
\text { corporação ao patrimônio } \\
\text { público e avaliação e auto- } \\
\text { rização do poder público. } \\
\text { Sobre condições para } \\
\text { cessão de pessoal da admi- } \\
\text { nistração pública para a OS. }\end{array}$ & $\begin{array}{l}\text { Inclui apenas } \\
\text { três itens que tratam } \\
\text { da natureza da OS } \\
\text { e da destinação de } \\
\text { recursos orçamen- } \\
\text { tários. }\end{array}$ & $\begin{array}{l}\text { Segue as mesmas } \\
\text { orientações das dire- } \\
\text { trizes da norma nacio- } \\
\text { proteção ao patrimô- } \\
\text { nio público. } \\
\text { o proposto na regra } \\
\text { estadual. }\end{array}$ \\
\hline Desabilitação & $\begin{array}{l}\text { Motivada por problemas } \\
\text { que vão da conduta ética } \\
\text { ao cumprimento do CG. } \\
\text { Ato do Poder Executivo. } \\
\text { Suspensão do CG antecede } \\
\text { desabilitação. }\end{array}$ & $\begin{array}{l}\text { Mesmo conteúdo da da } \\
\text { regra federal. }\end{array}$ & $\begin{array}{l}\text { Mesmo conteúdo } \\
\text { da regra estadual } \\
\text { (Goiás). }\end{array}$ \\
\hline
\end{tabular}

Fonte: Brasil (1998), São Paulo (1998) e Goiás (2005).

O contrato de gestão, instrumento de mediação entre contratado (OS) e contratante (poder público), define um conjunto de compromissos entre as partes. Em relação ao contratante, fixa os valores e formas de repasse dos recursos necessários ao desenvolvimento das atividades da OS. No tocante ao contratado, estabelece os objetivos e metas a serem alcançados durante um período de tempo (normalmente o ano fiscal) e informa sobre indicadores a serem utilizados para avaliar o cumprimento dessas metas, bem como a frequência com que essa avaliação será feita. No caso de São Paulo, essa avaliação é trimestral; em Goiás, ela é realizada a cada seis meses.

O primeiro contrato para administração do Huana foi formalizado no ano de 2006. Fixou-se como intervalo de tempo para revisão global do contrato de gestão o prazo de cinco anos. O ano de 2010 foi o da revisão e formulação de um novo contrato entre a Fundação de Assistência Social de Anápolis (Fasa) e a Secretaria de Estado da Saúde de Goiás. No período de vigência do primeiro contrato, foram elaborados termos aditivos de prorrogação de contrato e repactuação de metas. Nessa primeira versão do contrato, o gasto com pessoal foi fixado em $45 \%$ do total recebido pela OS. O contrato permite, ainda, que, na hipótese de captação de recursos de outras fontes, o estado possa deduzir dos recursos transferidos pela contratante o montante equivalente ao captado. 
O primeiro aditivo teve o objetivo de ajustar o contrato entre as partes, estabelecendo espaço para a renegociação de metas e a consequente revisão dos valores repassados à Fasa, que passaram de $\mathrm{R} \$ 26.194 .466,28$ para $\mathrm{R} \$ 21.600 .000,00$.

O segundo deles teve como finalidade estabelecer a manutenção da parceria, por intermédio da prorrogação do contrato, mantendo as cláusulas anteriores. O terceiro aditivo altera apenas o item que trata de recursos de investimentos, mantendo o percentual de $5 \%$ dos recursos destinados à unidade para esse fim, estabelecendo, entretanto, que a possibilidade de majoração desse percentual depende da expressa autorização da contratante. Não deixa claro se o uso desses $5 \%$ previstos no contrato também depende dessa autorização.

No ano de 2010, foi elaborada e aprovada nova proposta de contrato de gestão, com validade de um ano. O valor total do contrato foi estabelecido em $\mathrm{R} \$ 31.200 .000,00$. Esse valor representa um incremento de $19,08 \%$ em relação ao valor fixado no primeiro contrato e $44,4 \%$, considerando o valor estabelecido no primeiro termo aditivo. Os aspectos envolvendo o desempenho da OS e a revisão das metas serão objeto de discussão no tópico seguinte.

\section{Monitoramento e avaliação do desempenho da unidade}

O contrato de gestão, ao estabelecer objetivos e metas, informa os procedimentos a serem adotados para o seu alcance, que incluem a definição da meta de referência para cada item (base de comparação com o realizado) e os indicadores para sua mensuração. Nesse sentido, foram fixadas como metas de produção: número de pacientes atendidos, número de internações, número de pacientes atendidos no pronto-atendimento, número de atos médicos em ortopedia, número de exames e número de cirurgias. Outra meta adotada foi a relativa ao número de atos não médicos realizados pelos demais profissionais da unidade (enfermeiros, psicólogos, nutricionistas, assistentes sociais). Esses indicadores são avaliados com base na capacidade potencial de produção da unidade, considerados os seus recursos humanos e materiais. As metas de referências para esses procedimentos, ficaram distribuídas, conforme Tabela 1.

Foi incluído, ainda, um conjunto de indicadores de desempenho descritos no Quadro 2.

Para esses indicadores de desempenho, foram estabelecidas metas que servem de parâmetro para qualificação e avaliação desses indicadores, parâmetros descritos no Quadro 3. 
Tabela 1: Número de procedimentos previstos, segundo contrato de gestão 2005-2007

\begin{tabular}{l|c}
\hline \multicolumn{1}{c|}{ Procedimentos } & Metas previstas \\
\hline Pacientes & 11.232 \\
\hline Internações & 2.868 \\
\hline Pronto-atendimento & 108.000 \\
\hline Atos médicos em Ortopedia & 43.362 \\
\hline Exames e procedimentos diagnósticos (SADT) & 165.132 \\
\hline Cirurgias & 2.094 \\
\hline Atos não médicos & 301.740 \\
\hline
\end{tabular}

Fonte: Goiás (2010)

Quadro 2: Relação de indicadores de desempenho e fórmulas de cálculo

\begin{tabular}{|l|l|}
\hline Indicadores de desempenho & Fórmula de cálculo \\
\hline Taxa de infecção hospitalar & $\begin{array}{l}\text { Total de infecções no período/total de altas } \\
\text { e óbitos no mesmo período x } 100\end{array}$ \\
\hline Taxa de mortalidade global & $\begin{array}{l}\text { Total de óbitos no período/total de altas e } \\
\text { óbitos no mesmo período x 100 }\end{array}$ \\
\hline Taxa de ocupação hospitalar & $\begin{array}{l}\text { Total de pacientes-dia no período/total de } \\
\text { leitos no mesmo período x 100 }\end{array}$ \\
\hline Média de permanência hospitalar & $\begin{array}{l}\text { Total de pacientes-dia no período/interna- } \\
\text { ções no mesmo período }\end{array}$ \\
\hline Tempo médio de entrega de exames & $\begin{array}{l}\text { Data da solicitação do exame/data da rea- } \\
\text { lização do exame }\end{array}$ \\
\hline Satisfação da clientela & $\begin{array}{l}\text { Quantidade de avaliações entre bom e óti- } \\
\text { mo/total de pessoas pesquisadas x 100 }\end{array}$ \\
\hline Índice de resultado financeiro & $\begin{array}{l}\text { Receita total no período/despesa total no } \\
\text { mesmo período }\end{array}$ \\
\hline
\end{tabular}

Fonte: Goiás (2010)

Os indicadores de produção são estabelecidos considerando a capacidade física e de recursos humanos instalada. Com base no número total de horas por categoria profissional e nos recursos físicos disponíveis, estabelece-se a capacidade potencial de produção. Tomando como base o setor de Apoio Diagnóstico e Terapêutico, analisando esses dois recursos (horas/profissional e infraestrutura disponível), relacionando-os com os processos de trabalho destinados à produção de cada unidade/produto, define-se a capacidade potencial de produção de exames.

Com o propósito de fixar conceito e indicadores para qualificação dos resultados alcançados, adotou-se o termo eficácia como referência, aqui traduzido como capacidade da organização em alcançar as metas previstas, representada pela 
fórmula metas realizadas/metas previstas x 100. Considerando o conceito adotado, a classificação do desempenho da unidade ficou assim definida: maior que $100 \%$ alto desempenho; igual a $100 \%$ - desempenho esperado; menor que $100 \%$ e maior que $80 \%$ - próximo do esperado; menor que $80 \%$ e maior que $50 \%$ - moderado; menor que $50 \%$ - baixo desempenho (GoIÁs, 2010).

\section{Quadro 3: Metas de resultado esperado, segundo indicadores de desempenho estabelecidos}

\begin{tabular}{|l|l|}
\hline Indicadores de desempenho & Parâmetro de resultado \\
\hline Taxa de infecção hospitalar & Igual ou menor que $2 \%$ \\
\hline Taxa de mortalidade global & Igual ou menor que 4\% \\
\hline Taxa de ocupação hospitalar & Igual ou maior que $80 \%$ \\
\hline Média de permanência hospitalar & Não foi estabelecida meta \\
\hline Tempo médio de entrega de exames & Igual ou menor que 24 horas \\
\hline Satisfação da clientela & $\begin{array}{l}\text { Quantidade de avaliações entre bom e } \\
\text { ótimo/total de pessoas pesquisadas x } 100\end{array}$ \\
\hline Índice de resultado financeiro positivo & $\begin{array}{l}\text { Igual a 1 (quanto menor que 1, pior a } \\
\text { avaliação) }\end{array}$ \\
\hline
\end{tabular}

Fonte: Goiás (2010)

O acompanhamento da execução do contrato ficou sob a responsabilidade de uma comissão composta por membros da Secretaria de Estado da Saúde (SES-GO), representada pela Superintendência de Controle e Avaliação Técnica em Saúde (SCATS) e técnicos da Superintendência de Controle Interno (SCI). A frequência dessa avaliação é semestral.

A primeira consideração em relação aos dados apresentados é a baixa capacidade de cumprimento das metas de produção, com inversão significativa a partir de 2008. O período entre 2005 e 2007 é definido pelos entrevistados como um momento de transição para adaptação a um modelo novo, baseado na definição de resultados a serem alcançados. Importante ressaltar que o processo de ajuste das metas sinaliza vários aspectos do processo de implantação do modelo OS, considerando o caso Huana.

O primeiro deles é o longo intervalo de seis semestres para que fosse tomada a iniciativa de rever as metas pactuadas. Tal decisão se dá por força do termo aditivo assinado em março de 2008 , com as metas sendo revisadas para menos, segundo a Tabela 2.

Para 2010, o novo contrato de gestão estabeleceu novos ajustes nas metas com oscilações para mais, comparativamente às metas do período 2008-2009, conforme dados apresentados na Tabela 3. 
Tabela 2: Número de procedimentos previstos segundo contrato de gestão 2008*-2009 e variação percentual em relação aos valores 2005-2007

\begin{tabular}{l|c|c}
\hline Procedimentos & Metas previstas & \% variação \\
\hline Pacientes & $3.744^{* *}$ & $-66,6 \%$ \\
\hline Internações & 2068 & $-27,9 \%$ \\
\hline Pronto-atendimento & 21.200 & $-80,3 \%$ \\
\hline Atos médicos em Ortopedia & $14.454^{* *}$ & $-66,6 \%$ \\
\hline Exames e procedimentos (SADT) & 56.964 & $-65,5 \%$ \\
\hline Cirurgias & 1300 & $-37,9 \%$ \\
\hline Atos não médicos & 35.600 & $-88,2 \%$ \\
\hline
\end{tabular}

Fonte: Elaboração própria.

* No ano de 2008, utilizaram-se dois conjuntos de metas, um para o período janeiro/fevereiro e outro para o período março/junho. A opção foi adotar os indicadores utilizados para o período março/junho, por representar $2 / 3$ do semestre (mais representativo, portanto).

** Metas do período janeiro/fevereiro mantidas para março/junho.

Tabela 3: Número de procedimentos previstos segundo contrato de gestão 2010 e \% de variação em relação 2008-2009

\begin{tabular}{l|c|c}
\hline Procedimentos & Metas Previstas & \%variação \\
\hline Internações & 2750 & $+24,8 \%$ \\
\hline Pronto-atendimento & 26.800 & $+20,9 \%$ \\
\hline Exames e procedimentos (SADT) & 114.000 & $+49,9 \%$ \\
\hline Cirurgias & 2480 & $+46,3 \%$ \\
\hline Atos não médicos & 75.000 & $+110,6 \%$ \\
\hline
\end{tabular}

Fonte: Goiás (2010).

É importante destacar que alguns procedimentos, como cirurgias e exames, pressionam os gastos da unidade. Procedimentos inferiores a essa média de aumento, como internações, também são de alto custo agregado, por serem exigentes no uso intensivo de mão de obra.

A despeito da variação positiva das metas de 2010 frente ao período anterior (2008-2009), quando comparadas com aquelas estabelecidas para o período 2005-2007 (Tabela 1), apenas a previsão de atos cirúrgicos variou positivamente. A trajetória errática dos resultados pactuados sinaliza a dificuldade encontrada por contratante e contratada em relação aos critérios utilizados para cálculo da capacidade potencial de produção.

Segundo o que estabelece a regra de criação das OS, a pactuação de metas é negociada entre as partes (como de resto em qualquer contrato), por meio de comissão com representantes nomeados por cada uma dessas. Como responsável 
pela regulação do sistema, a SES-GO deveria propor essas metas, considerando seu papel gestor e o conhecimento técnico acumulado sobre o processo de planejamento e programação de sistemas e serviços.

Não há consenso sobre como foram estabelecidas essas metas, com depoimentos apontando para a utilização de outras unidades como parâmetro para esses cálculos ou para a demanda potencial a ser atendida. O baixo desempenho verificado no período 2005-2007 levou a Comissão de Avaliação a propor à direção da OS a revisão das metas e o consequente ajuste dos valores a serem repassados, conforme termo aditivo de 2008 .

Interessante observar que, apesar da longa experiência da mantenedora (Fasa) com a administração hospitalar (gerenciamento da Santa Casa de Anápolis), essa demonstra dificuldade em estabelecer critérios e parâmetros para o cálculo de suas metas. $O$ fato demonstra que as duas instituições envolvidas nesse processo careciam de experiência com modelos de gestão focados em resultados. Essa situação apresenta um complicador quando se observa a relação entre metas físicas e valores transferidos, que diz respeito à inexistência de um sistema de custo que permita estabelecer valores de referência para os procedimentos adotados. Os valores utilizados são os praticados por tabela do SUS, que informa os valores de pagamento da produção da unidade a ser feita pelo sistema.

Por outro lado, o processo de habilitação deveria ser revisado, com um novo desenho que promovesse a seleção de entidades com base em processo licitatório que avaliasse as entidades candidatas ao contrato de gestão, considerando: tempo de experiência na gestão de serviços de saúde, resultados no desempenho dessa função e em proposta de orçamento e metas para a unidade.

Por fim, seria importante considerar que a avaliação da produção em saúde tem características próprias que a diferenciam da produção de bens e serviços em outras áreas, como, por exemplo: a produção e o consumo se dão de forma simultânea (não é possível estocar); a matéria prima dessa produção são os sujeitos individuais e coletivos; a natureza interpessoal da atividade; o consumo é singular (não existem duas consultas iguais, mesmo para pacientes com a mesma patologia). A avaliação da capacidade produtiva, portanto, deve considerar esses elementos, além da representação dos usuários sobre o serviço e do componente político do processo de gestão do sistema.

\section{Gestão do processo de aquisição de bens e serviços e contratação de recursos humanos}

A busca por novas formas de gestão de unidades hospitalares no SUS tem como motivação a necessidade de dar mais celeridade ao processo de aquisição de bens e serviços, bem como a de contratação de pessoal. A contratação de pessoal, 
nesse caso, segue o fluxo adotado por empresas do setor privado, por meio de recrutamento e seleção direta de candidatos, considerando o perfil adequado aos cargos e funções a serem preenchidas. No caso do Huana, o recrutamento de candidatos foi feito via imprensa e a seleção mediante avaliação de currículos. Todos os contratados são celetistas, não sendo admitida a precarização de vínculos. O padrão de remuneração dos profissionais médicos e de enfermagem dessa OS segue os valores estabelecidos para pessoal da SES-GO, conforme Tabela 4.

Tabela 4: valores de remuneração para médicos e enfermeiras na SES-GO, 2010.

\begin{tabular}{l|c|c}
\hline Cargo & Carga horária & Salário base \\
\hline Médico & 20 horas semanais & $\mathrm{R} \$ 2.500,00$ \\
\hline Enfermeiro & 30 horas semanais & $\mathrm{R} \$ 2.500,00$ \\
\hline Técnico de enfermagem & 30 horas semanais & $\mathrm{R} \$ 1.631,60$ \\
\hline
\end{tabular}

Fonte: Goiás, 2010

Não foram apresentados dados sobre rotatividade da força de trabalho para essa unidade, apenas uma referência por representante da administração informando ser essa muito baixa. A questão que se coloca é sobre o que pode ser fator de motivação para essa baixa rotatividade. Seria interessante investigar a fundo os fatores que incidem sobre essa situação.

O processo de aquisição de bens e serviços é realizado de maneira simplificada a partir de consulta à rede de fornecedores e cotação de preços dos itens solicitados. O tempo de duração dedicado a contrato de bens e serviços é, em média, de uma semana, o que reduz sensivelmente o dispêndio de tempo e recursos para realização dessa atividade, com poucas pessoas e procedimentos comprometidos com atividade-meio.

A compra de equipamentos e materiais é realizada mensalmente e concentrada apenas nos itens necessários aos serviços e ações para esse horizonte de tempo, permitindo que os estoques girem com maior rapidez e evite-se, assim, desperdício de dinheiro (que inclui o risco de descarte de material por perda de prazo de validade, comum no setor público). As vantagens competitivas das OS sobre unidades da administração direta residem, em boa parte, na simplificação desses processos de suprimento.

A OS possui um regulamento de compras, que é o instrumento que orienta a maneira de fazer essas aquisições e que, em síntese, indica a necessidade de observar as melhores condições de preço e qualidade do produto a ser adquirido. $O$ acompanhamento da execução física e financeira da unidade é feito, internamente, pela Comissão de Avaliação do contrato de gestão, além dos meios de controle 
externo a que está submetida em função da natureza pública do hospital. A despeito dos dados e informações levantados neste trabalho, os autores consideram necessário o desenvolvimento de novos estudos sobre esse modelo de gestão no Estado de Goiás.

\section{Considerações finais}

Os modelos de gestão baseados em novas formas de relação entre público e privado vêm sendo implementados no Brasil em diversas áreas de atuação da administração pública. As parcerias público-privadas (PPP) surgiram e se desenvolveram no campo da infraestrutura (principalmente no setor de transporte) e avançaram para a oferta de serviços sociais. A Bahia foi o primeiro estado brasileiro a implantar PPP na área de saúde, com a construção e compra de equipamentos de uma unidade hospitalar por empresas privadas, que ganharam com isso o direito de explorar os serviços ofertados por esse hospital por um período de tempo, de modo tal que possam obter o ressarcimento (com lucros) do investimento feito.

No Estado de Goiás, essa experiência se inicia com a implantação do modelo OS no Centro de Reabilitação e Readaptação (Crer) e vem sendo expandida para outras unidades hospitalares. Atualmente, o novo governo vem trabalhando na implantação de uma proposta de PPP à semelhança da proposta da Bahia, tendo formado grupo técnico de trabalho para o desenvolvimento desse projeto.

Os dados e informações levantados no presente trabalho assinalam algumas vantagens competitivas do modelo OS, tais como a flexibilidade no processo de aquisição de bens e serviços, implantação de cultura de monitoramento e avaliação de desempenho, e estabelecimento de metas de referência em relação ao uso dos recursos (critérios de eficiência). Por outro lado, observam-se algumas dificuldades internas ao setor publico em acompanhar e avaliar os objetivos e metas acordados nos contratos de gestão. Esse problema sugere a necessidade de investimentos no fortalecimento de competência técnica para implantação de modelos gerenciais focados em resultados.

Uma questão importante nesse processo diz respeito à integração entre metas físicas e financeiras. Estabelecer, no contrato de gestão, o valor global a ser repassado a uma OS para gerenciar uma unidade hospitalar implica ter uma avaliação do custo de cada procedimento a ser realizado. Os documentos consultados, bem como os informantes entrevistados, não fazem referência à existência desses sistemas, informando que as metas e valores foram adotados com base em comparação com outra unidade de mesma natureza e porte maior (Hospital de Urgências de Goiás Hugo). Obviamente, como o padrão de remuneração do SUS segue valores próprios de sua tabela, esses serão confrontados com os custos reais apurados por sistemas de custos, para fins de exercício de ajustes na tabela. 
Os critérios e formas de seleção de parcerias deveriam ser revistos, o poder discricionário do chefe do Executivo talvez não seja suficiente para que se façam as melhores escolhas das OS a serem contratadas. A escolha precisa se dar com base em critérios como: experiência das organizações candidatas; propostas técnicas, avaliadas por profissionais especializados na área de administração hospitalar; controle e avaliação e gestores com experiência acumulada nestes modelos de gestão. Esse procedimento de escolha criteriosa deveria ser a regra a ser adotada.

O acompanhamento do processo de implantação e desenvolvimento desses modelos demanda, com base no caso aqui analisado, consultoria externa com especialização na área. O Estado de São Paulo, o primeiro a adotar o modelo OS, ancorou o processo de implantação das organizações sociais de saúde em consultoria externa (Barcelona) para desenvolvimento do projeto.

Sugere-se, ainda, a continuidade de trabalhos como o que foi aqui desenvolvido junto a outras unidades que incorporaram o modelo OS e a comparação entre essas experiências, a fim de identificar o benchmarking que possa servir de referência para o conjunto de serviços que operem nessa modalidade.

\section{Referências bibliográficas}

BARBoSA, N. B.; ELIAS, P. E. M. As organizações sociais como forma de gestão público/ privado. Revista Ciência e Saúde Coletiva, Rio de Janeiro, v. 15, no 5, p. 2483 - 2495, 2010.

BRASIL. Lei no 9.637, de 15 de maio de 1998. Dispõe sobre a qualificação de entidades como organização social. Brasília, 1998.

Ministério da Saúde. Portaria no 399, de 22 de fevereiro de 2006. Consolidação do SUS e aprova as Diretrizes Operacionais. Disponível em: <http:// dtr2001.saude.gov.br/sas/PORTARIAS/Port2006/GM/GM-399.htm> Acesso em: 20 mai. 2013.

Ministério da Saúde. Temático Prevenção de Violência e Cultura de Paz III. Organização Pan-Americana da Saúde. Brasília, 2008. 60p.

Ministério da Saúde. Decreto no 7.508/2011. Disponível em < http:// www.planalto.gov.br/ccivil_03/_ato2011-2014/2011/decreto/D7508.htm. Acesso em: 15 mar. 2014.

Ministério da Previdência Social. Estudos e pesquisas da Secretaria de Políticas da Previdência Social. Brasília, 2009.

BRESSER PEREIRA, L. C. Democracia, Estado Sociale Democracia. Revista de Administração de Empresas, São Paulo, v. 50, no 1, p. 112 - 116, 2010.

CAMPos, Gastão W. S. et al. (orgs.). Tratado de Saúde Coletiva. São Paulo - Rio de Janeiro: Fiocruz/Hucitec, 2007. 
CARneiro Júnior, N.; EliAs, P. E. M. Controle público e equidade no acesso a hospitais sob gestão pública não estatal. Revista de Saúde Pública, São Paulo, v. 40, no 5, p. $914-920,2006$.

Cohn, A.; ElıAS, P. E. M. Saúde no Brasil: políticas e organização de serviços. 5ạ edição. São Paulo: Cortez, 2003.

CORRÊA, I. M. Planejamento estratégico e gestão pública por resultados no processo de reforma administrativa do Estado de Minas Gerais. Revista de Administração Pública, Rio de Janeiro, v. 41, no 3, p. 487 - 504, 2007.

COTTA, Elaine. Sai do papel a primeira PPP do setor saúde no Brasil. Disponível em: <www.brasileconomico.com.br>. Acesso em: 26 abril de 2012.

DATASUS. Indicadores e dados básicos. Disponível em www.datasus.gov.br. Acesso em em 23 de setembro de 2011.

Sistema de Informação em Mortalidade. Disponível em www.datasus. gov.br. Acesso em 15 de agosto de 2011.

FASA. Relatório sobre capacidade instalada do Huana. Anápolis, 2010 (mimeo).

GoIÁs. Lei no 15.503, de 28 de dezembro de 2005. Dispõe sobre a qualificação de entidades como organização social. Goiânia, 2005.

Secretaria de Estado da Saúde de Goiás. Relatório de avaliação da execução do contrato de gestão. Goiânia, 2010 (mimeo).

Secretaria de Estado da Saúde. Termo aditivo ao Contrato de Gestão do Crer. Goiânia, 2012 (mimeo).

Governo do Estado de Goiás. Lei no 18.831, de 30 de dezembro de 2013. Dispõe sobre a qualificação de entidades como organização social. Disponível em <www.gabinetecivil.go.gov.br>. Acesso em 19 de junho de 2014.

Secretaria de Estado da Saúde. Organizações sociais de saúde. Disponível em <www.saude.go.gov.br>. Acesso em 18 de junho de 2014.

IBge - Instituto Brasileiro de Geografia e Estatística. Censo 2010. Disponível em: $<w w w . i b g e . g o v . b r>$. Acesso em 10 de março de 2013.

IBAÑEZ, N. et al. Organizações sociais de saúde: o modelo do Estado de São Paulo. Ciência e Saúde Coletiva, São Paulo, no 6, p. 301-404, 2001.

RIBEIRO, G. S. Problemas de saúde da população brasileira e seus determinantes. In: PAIM, J. S.; ALMEIDA-FILHo, N. (Org.). Saúde coletiva: teoria e prática. Rio de Janeiro: Medbook, 2014.

SÃo PAUlo. Lei Complementar no 846, de 4 de junho de 1998. Dispõe sobre a qualificação de entidades como organização social. São Paulo, 1998.

Tribunal de Contas do Estado (TCE). Comparação de hospitais paulistas.

2010. Disponível em <www.tce.sp.gov.br>. Acesso em 18 de junho de 2014. 


\section{Nelson Bezerra Barbosa}

Psicólogo; Doutor em Saúde Pública (FMUSP); Docente do Curso de Medicina e do Mestrado Multidisciplinar em Sociedade, Tecnologia e Meio Ambiente do Centro Universitário de Anápolis (UniEvangélica); Gestor Público da SES-GO; Coordenador do Projeto de Pesquisa. Contato: nelsonbbarbosa@gmail.com

Helen de Lima

Enfermeira, Mestre em Saúde do Trabalhador (UFMG), Doutoranda do Programa de Pós-graduação em Ciências da Saúde (UFG), Docente do Curso de Medicina do Centro Universitário de Anápolis (UniEvangélica), Técnica do Laboratório Central (Lacen) da SES-GO. Contato: helendelima@gmail.com

Andrei Machado Viegas da Trindade

Discente do Curso de Medicina do Centro Universitário de Anápolis (UniEvangélica), bolsista Pibic. Contato: andreimachado.uni@gmail.com

Natália Vieira Dias

Discente do Curso de Medicina do Centro Universitário de Anápolis (UniEvangélica), bolsista Pibic. Contato: nataliadias.uni@gmail.com

Mariana Vilela de Castro

Discente do Curso de Medicina do Centro Universitário de Anápolis (UniEvangélica), bolsista Pibic. Contato: mariana.medicina.unievangelica@gmail.com

Caroline Kwiatkoski dos Santos

Discente do Curso de Medicina do Centro Universitário de Anápolis (UniEvangélica), bolsista Pibic. Contato: carolinekwiatkoski@yahoo.com.br 